\title{
Contaminated Generic Non-approved Remdesivir Vials: New Risk in Treatment of COVID-19
}

\author{
Cökhan Aygün' ${ }^{1}$ (D), Oğuzhan Kayhan² (D), Fatouma Moustapha Houssein³ (D), Seval Ürkmez² (D), \\ Ahmet Furkan Kurt ${ }^{3}$ (D) Bilgül Mete ${ }^{3}$ \\ 1 Department of Medical Microbiology, İstanbul University-Cerrahpaşa, Cerrahpaşa School of Medicine, İstanbul, Turkey \\ 2 Department of Anaesthesiology and Reanimation, İstanbul University-Cerrahpaşa, Cerrahpaşa School of Medicine, \\ istanbul, Turkey \\ 3 Department of Infectious Diseases and Clinical Microbiology, Istanbul University-Cerrahpaşa, Cerrahpaşa School of \\ Medicine, İstanbul, Turkey
}

Dear Editor,

Remdesivir is a novel nucleotide analogue antiviral drug with in vitro activity against severe acute respiratory syndrome coronavirus 2 (SARS-CoV-2) (1). Food and Drug Administration (FDA) and Drug Controller General of India have authorized the emergency use for the treatment of COVID-19 under an Emergency Use Authorization (EUA) (2).

The original trademark name of remdesivir with proven and approved efficacy developed by Gilead is Veklury ${ }^{\circledR}$. Veklury ${ }^{\circledR}$ is licenced in over 50 countries around the world, including the United States, European Union, Japan, Canada, Australia. Veklury ${ }^{\circledR}$ has not yet been licenced by the Ministry of Health in Turkey. Gilead supplied 17378 vials of Veklury ${ }^{\circledR}$ to the Health of Ministry of Turkey free of charge. However, Gilead announced that illegal products which are likely to contain remdesivir have been entered our country and sold on the black market (3).

We notified that relatives of some patients provided remdesivir preparations which were manufactured in India and not licensed in our country. Upon the information which was stated in the press release by Gilead and the side effects developed after remdesivir use reported from other institutions (fever, increase in procalcitonin), we have decided to analyze these vials microbiologically.

Three different CoviforTM vials (Batch no: RC2989) manufactured by Hetero Healthcare Limited in India (figure) were analyzed. After opening the unused vials and disinfection with 70\% alcohol, $1 \mathrm{ml}$ drug sample was inoculated into BACTEC pediatric culture vials (Becton Dickinson, USA). Bacterial growth was detected in the pediatric culture vials 9-12 hours after inoculation. Subcultures on chromogenic medium (Becton Dick-

Corresponding Author: Gökhan Aygün

\section{E-mail:}

gokhanaygun67@yahoo.com

Received: December 04, 2020 Accepted: December 27, 2020 Published: December 31, 2020

\section{Suggested citation:}

Aygün $\mathrm{G}$, Kayhan O, Houssein FM, Ürkmez S, Kurt AF, Mete B. Contaminated Generic Nonapproved Remdesivir Vials: New Risk in Treatment of COVID-19. Infect Dis Clin Microbiol 2020; 3 : 181-183.

DOI: $10.36519 / \mathrm{idcm} .2020 .0031$ 
inson, USA)revealed the growth of two different Gram-negative rods. All microbiological studies were performed in the Biosafety cabinet class 2 and in accordance with the principles of Good Microbiological Practices. Sterility of pediatric blood culture bottles and media used were checked before use. Disposable, single-use syringes were used to take samples from the drug vials, and sterile disposable plastic loops were used to examine the isolated bacteria. Bacterial isolates were identified using conventional methods and MALDI-TOF-MS (Becton Dickinson, USA). One of all isolates was Klebsiella oxytoca and the other Enterobacter asburiae/bugandensis (score value: 2.182/2.099). Antibiotic susceptibilities were determined using the disk diffusion method according to the EUCAST breakpoints (Table 1).

Various nosocomial infections related to drug contamination have been reported in the literature. Except for blood and blood products and total parenteral solutions, heparin, propofol, albuterol, fentanyl and many other drug and solutions were determined as source of infections. Burkholderia cepacia, Enterobacter spp. Ralstonia picketii, Serratia spp., Staphylococcus aureus and Klebsiella spp. are among the most common microorganisms responsible for contamination (4). In September 2012, upon the largest health care-associated outbreak in the USA, three lots of methylprednisolone were contaminated with a mold defined as Exserohilum rostratum and led to fungal meningitis (5). Upon this outbreak, FDA and the Centers for Diseases Control and Prevention have identified bacterial and/ or fungal contamination in unopened vials of bet-
Table 1. Antibiotic susceptibilities of the isolated bacteria

\begin{tabular}{|l|c|c|}
\hline Ampicillin & $\begin{array}{c}\text { Klebsiella } \\
\text { oxytoca }\end{array}$ & $\begin{array}{c}\text { Enterobacter } \\
\text { asburiael } \\
\text { bugandensis }\end{array}$ \\
\hline Amoxicillin-clavunate & $\mathrm{R}$ & $\mathrm{R}$ \\
\hline Cefotaxime & $\mathrm{S}$ & $\mathrm{R}$ \\
\hline Ceftazidime & $\mathrm{S}$ & $\mathrm{S}$ \\
\hline Cefepime & $\mathrm{S}$ & $\mathrm{S}$ \\
\hline Imipenem & $\mathrm{S}$ & $\mathrm{S}$ \\
\hline Amikacin & $\mathrm{S}$ & $\mathrm{S}$ \\
\hline Gentamicin & $\mathrm{S}$ & $\mathrm{S}$ \\
\hline Ciprofloxacin & $\mathrm{S}$ & $\mathrm{S}$ \\
\hline
\end{tabular}

S: Susceptible; R: Resistant

amethasone, cardioplegia, and triamcinolone solutions distributed and recalled from New England Compounding Center (6).

In light of these findings, we think that the drug was most probably contaminated during the manufacturing process. It should be kept in mind that drugs provided without the approval and supervision of health authorities may have significant risks and should be avoided.
Peer-review: Externally peer-reviewed

Conflict of Interest: The author have no conflict of interest to declare.
Financial Disclosure: The author declared that this study has received no financial support. 


\section{REFERENCES}

1 Wang M, Cao R, Zhang L, Yang X, Liu J, Xu M, et al. Remdesivir and chloroquine effectively inhibit the recently emerged novel coronavirus (2019-nCoV) in vitro. Cell Res 2020; 30: 269-71.

2 U. S Food and Drug Anministration. Highlights of prescribing information- VEKLURY® (remdesivir) injection, for intravenous use Initial U.S. Approval: 2020. (cited 2020 December 4) Available from: URL: https://www.accessdata.fda.gov/drugsatfda docs/label/2020/2147870rig1s000lbl.pdf

3 Gilead Siciences. Press Release Nov 17 2020. (cited 2020 December 4) Available from: URL: https://www.klimik.org.tr/ wp-content/uploads/2020/11/Remdesivir-Basin-Duyurusu.pdf.
4 Vonberg RP, Gastmeier P. Hospital-acquired infections related to contaminated substances. J Hosp Infect 2007; 65: 15-23.

5 Kauffman CA, Malani AN. Fungal infections associated with contaminated steroid injections. Microbiol Spectr 2016; 4.

6 (cited 2020 December 4) https://wayback.archive-it. org/7993/20170112164908/http://www.fda.gov/Safety/MedWatch/SafetyInformation/SafetyAlertsforHumanMedicalProducts/ucm323946.htm 